\title{
Reply to Sandin: The Paradox of Precaution Is Not Dispelled by Attention to Context
}

\author{
SØREN HOLM
}

In "A Paradox out of Context: Harris and Holm on the Precautionary Principle," Sandin criticizes the earlier paper "Extending Human Lifespan and the Precautionary Paradox" wherein John Harris and I argued that the precautionary principle (PP) is incoherent. ${ }^{1}$ These criticisms offer me the possibility to briefly expand and clarify some of our previous arguments, and to show that the paradox of precaution is not dispelled by attention to context as Sandin maintains. Even when context is fully acknowledged, application of the PP will still lead to paradox and paralysis.

\section{The Criticisms Summarized}

Sandin raises a number of criticisms of our position, but I take the following three to be the main criticisms. First, that the PP, although existing in different and possibly ill-defined versions, actually works as a decisionmaking principle when properly interpreted. Second, that our refutation of the epistemic version of the PP is misdirected because no one holds the principle in this form, and furthermore it is fallacious. Third, that our refutation of the PP as a principle of choice, or in Sandin's terminology a prescriptive principle, is an example of what Sandin calls the argument from absolutism, and can be dispelled by proper attention to context. I will briefly discuss each of the three objections to our position and show why they fail.

\section{The Properly Defined Precautionary Principle Works?}

Is the problem with the PP only a problem of specification or definition? Sandin admits that we should perhaps give up talking about the PP with the definite article because there are many different versions of the $\mathrm{PP}$, but he quickly reverts to the use of the definite article, as if there was only one canonical version. Be that as it may, he goes on to point out that policymakers, legislators, and courts are slowly developing interpretations of the PP and cites the European Commission for the views that "it would be wrong to conclude that the absence of definition has lead to legal uncertainty," and that " $[t]$ he Community authorities' practical experience with the precautionary principle and its judicial review make it possible to get an everbetter handle on the precautionary principle." 2 What Sandin forgets to tell us is that the European Commission is not a disinterested party. The European Union relies on the PP in a number of trade disputes with the United States and other parties, currently being decided in panels of the World Trade Organization. The Commission communication that is cited is at least partly an attempt to bolster 
the credentials of the PP in those disputes. The Commission itself makes this point rather explicitly on page 9 of the Communication just before the sections that Sandin quotes: "The Commission also wishes to stress in this Communication that, far from being a way of evading obligations arising from the WTO Agreements, the envisaged use of the precautionary principle complies with these obligations." 3

We can therefore not take the word of the Commission as the gospel truth concerning the ease of interpreting and specifying the PP.

We still lack any reliable evidence that the PP is easy to apply when one keeps context in mind, and if such evidence is forthcoming we would need to know whether the PP applied by the decisionmakers has any likeness to the versions of the PP discussed now. The so-called "PP" that is actually used may be as far from the PP as a simple statable principle, as current UK jurisprudence on the killing of human beings is from "Thou shalt not kill."

\section{The Criticism of the Epistemic Version of the Principle Is Fallacious}

Sandin makes three points against our analysis of a possible epistemic version of the PP: (1) that no one actually holds the PP as an epistemic principle concerning belief; (2) that the epistemic versions people do hold are concerned with which propositions to act upon, not which propositions to believe; and (3) that a simple counterexample can show our analysis to be faulty anyway.

With regard to the first and second of Sandin's criticisms, it is initially important to note that even if he is right, it will not get the PP off the incoherence hook. If the PP is an epistemic rule, our original arguments showed that an epistemic PP concerned with beliefs will lead us to include many false beliefs in our belief system. These arguments will work just as well to show that Sandin's preferred epistemic PP concerned with which propositions to act upon will lead us to act wrongly/counterproductively/against the common good, and so forth.

Sandin's epistemic PP is just as hopeless a principle as our epistemic PP.

With regard to his third claim, it allows me to make an important clarification. Sandin points out that it is not only the number of correct beliefs in a belief system that counts, and that our elliptic statement that applying the epistemic PP will lead us to include a large number of false beliefs in our belief system is not enough to disqualify the PP as an epistemic principle. A belief system might be better than another if it, along with some trivial false beliefs, contains some important true beliefs. This is obviously true, but the conclusion Sandin draws is highly misleading. In the case of the epistemic PP, the situation is exactly the reverse, as in Sandin's counterexample. What the epistemic PP will do is make us adopt false beliefs about important issues, not about trivial issues, because the proponent of the PP would presumably not wish to invoke it in trivial matters. The epistemic PP will therefore produce a belief system with trivial truths and important falsehoods. It is thus still clear that the PP is an incoherent epistemic principle, as is any principle that negatively affects the ratio between important truths and important falsehoods in our belief system.

\section{The Absolutist Objection}

Sandin identifies our argument against the PP as a principle of choice and merely a version of what he calls "the argument from absolutism," which "says that the precautionary principle, 
at least some versions of it taken literally, will prohibit every action, and thus offer no action guidance whatsoever." And he further states that any force of the argument from absolutism can easily be dispelled because (1) it relies on a literal (mis)reading of the PP, and (2) the real PP involves a specification of the precautionary action, a specification of the threat context, and a specification of the level of prior evidence of possible harm necessary to trigger the application of the PP.

An initial response to this claim is to point out that there are statements of the PP in official binding treaties that seem to support a literal and absolutist reading. In the 1992 Convention on the Protection of the Marine Environment of the Baltic Sea Area we can, for instance, read the following in Article 3, subsection 2:

The Contracting Parties shall apply the precautionary principle, i.e., to take preventive measures when there is reason to assume that substances or energy introduced, directly or indirectly, in the marine environment may create hazards to human health, harm living resources and marine ecosystems, damage amenities or interfere with other legitimate uses of the sea even when there is no conclusive evidence of a causal relationship between inputs and their alleged effects. ${ }^{4}$

The "specification" of the threat context here is so wide-ranging, from human health and the environment, to amenities or interference with other legitimate uses, that it is difficult to give it a nonabsolutist reading. If we had chosen to argue against this expansive version of the PP, endorsed by the 10 ratifying parties to the convention, which happens to include the European Union, our original paper could have been very much shorter.

One might also wonder why a literal reading of the PP is wrong. Are principles, at least important prescriptive principles, not supposed to be read literally? If they are not supposed to be read literally should we not instead call them rules of thumb or guiding metaphors or something other than principles? Even in the case of prima facie principles, the literal reading is the one we have to do for each principle, before we can start prioritizing between them.

Sandin's assertion that our approach is absolutist must partly rely on a misreading of our article, because the version of the PP that we argue against and show to be incoherent contains exactly the specifications that Sandin wants:

PP1: When an activity raises threats of
serious and both irreversible and ir-
remediable harm to human health or
the environment, precautionary mea-
sures which effectively prevent the pos-
sibility of harm (e.g. moratorium,
prohibition etc.) shall be taken even if
the causal link between the activity
and the possible harm has not been
proven or the causal link is weak and
the harm is unlikely to occur.

Here we have a specification of the precautionary action, of the threat context (human health or the environment) and of the threat threshold, and implicitly of the prior level of knowledge necessary to activate the PP.

Sandin also classifies our approach as absolutist because we point out that there may be an infinite regress of precaution in certain cases where scientific uncertainty exists at the beginning of a new development and at every subsequent step in the development process. He does, however, strangely fail to realize that his favorite remedies would not have broken the regress in the concrete example we discuss, the case of GM plants. Even if a PP specified in the threat dimension is applied in this case, for instance, 
restricting application to the context of environmental degradation, the regress would still run its course, and a specification of level of prior evidence would not help either. At all points in the development, important risks of the next step have been identified, risks that could trigger the PP and stop further development. This was also true at the very beginning. At the point just before the first GM plant was produced, important risks had been identified with "a reasonable scientific foundation." That this foundation was extrapolation and speculation does not necessarily show it not to be reasonable, because we are talking about a point in time when very little empirical knowledge existed.

\section{The Argumentative Version of the Principle}

Sandin mentions one version of the PP that John Harris and I did not consider in our article, the argumentative version, which is a principle for what reasons or arguments are valid, and he points to principle 15 of the Rio Declaration as an example of this version. Principle 15 states that "lack of full scientific certainty shall not be used as a reason for postponing costeffective measures to prevent environmental degradation." For the sake of completeness, it is worth pointing out that this version of the PP is also incoherent. How can we know that measures are cost-effective in a situation where there is sufficient scientific uncertainty to make the PP applicable?

\section{Conclusion}

As I have shown briefly above, all of Sandin's main arguments against the analysis of the PP that John Harris and I presented in our earlier paper fail-either because they are themselves fallacious or because they fail to take into account some of the aspects of our analysis. If anyone is guilty of knocking down straw men, it is Sandin and not Harris and Holm.

The PP is incoherent and no amount of context can ever make the incoherent coherent.

What we need to do is give up the idea that there is a coherent and worthwhile PP to be found, defined, or specified, and instead start discussing how we can make rational and reasonable policy decisions in situations of great scientific uncertainty. It is unlikely that any single principle will give us the answer to that question.

\section{Notes}

1. Harris J, Holm S. Extending human lifespan and the precautionary paradox. Journal of Medicine and Philosophy 2002;27(3):355-68.

2. Commission of the European Communities (CEC). 2000. Communication from the Commission on the precautionary principle. COM/2000/ 0001/final p. 10.

3. See note 2, CEC 200:9.

4. Convention on the Protection of the Marine Environment of the Baltic Sea Area, 1992 (Helsinki Convention) Jul 2004 ed. Helsinki: HELCOM p. 4.

5. See note 1, Harris, Holm 2002:359. 